\title{
HILGARDIA
}

A Journal of Agricultural Science Publisbed by the California Agricultural Experiment Station

CONTENTS

FACTORS INFLUENCING THE RESULTS OF FUMIGATION OF THE CALIFORNIA RED SCALE

D. L. IINDGREN

INHERITANCE OF RESISTANCE TO HYDROCYANIC ACID FUMIGATION IN THE CALIFORNIA RED SCALE

R. C. DICKSON

UNIVERSITY OF CALIFORNIA • BERKELEY, CALIFORNIA 


\title{
H I L G A R D I A
}

A Journal of Agricultural Science Published by

the California Agricultural Experiment Station

VoL. 13

JANUARY, 1941

No. 9

\section{FACTORS INFLUENCING THE RESULTS OF FUMIGATION OF THE CALIFORNIA RED SCALE ${ }^{1,2}$}

\author{
D. L. LINDGREN ${ }^{3}$
}

\section{INTRODUCTION}

In the fumigation of the California red scale, Aonidiella aurantii (Mask.), with hydrocyanic acid gas ( $\mathrm{HCN})$, there are many variable factors that affect the results. Most of these factors are impossible to control under field conditions, and thus their range varies greatly and their relative importance is difficult to measure. Even under controlled laboratory conditions, uniform results are difficult to achieve with red scale obtained in the field, owing to the variation in the resistance of different populations and also to the relative resistance of the different ages of red scale to $\mathrm{HCN}$.

Considerable work has been conducted on the resistance of the red scale to HCN gas. Quayle (1938) " has reviewed and discussed this question and has shown that there are two strains of red scale present in the citrus orchards of southern California: one, the nonresistant, which is relatively easy to kill by $\mathrm{HCN}$ fumigation; and another, the resistant, which is more difficult to kill by HCN fumigation. Even though these two strains have been reared under identical conditions in the laboratory for more than three years, the differences in resistance to $\mathrm{HCN}$ are just as great as they were in the original colonies.

Factors affecting fumigation results, such as temperature and humidity (Quayle and Rohrbaugh, 1934), exposure of scale insects to sublethal concentrations of HCN before regular fumigation (Gray and

\footnotetext{
${ }^{1}$ Received for publication January 23, 1940.

${ }^{2}$ Paper no. 418, University of California Citrus Experiment Station, Riverside, California.

${ }^{3}$ Assistant Entomologist in the Experiment Station.

"See "Literature Cited" at the end of the paper for complete data on citations, which are referred to.in the text by author and date of publication.
} 
Kirkpatrick, 1929; Pratt, Swain, and Eldred, 1931; Moore, 1933; Lindgren, 1938), stages of insects (Quayle, 1920; Moore, 1934), length of exposure to HCN (Swain, 1918; Kirkpatrick, 1939), and type of concentration (Pratt, Swain, and Eldred, 1931; Cupples, 1933; Moore, 1933 ; Lindgren, 1938), have been studied both in the laboratory and in the field. The results obtained by the investigators have not always been in agreement, owing probably to a large extent to the fact that the scales used for experimental purposes were obtained from the field in several or many different groves. It is now well known that the red scales may vary from grove to grove in their susceptibility to HCN. Thus workers are not justified in comparing results obtained from a given treatment of red scale gathered from one grove with results obtained from other treatments of red scale gathered from another grove, unless the scales from the two groves have been determined beforehand to be similar in their reaction to HCN. To overcome this difficulty, two strains of red scale reared in insectproof rooms under identical conditions have been used as a source of supply for all experimental fumigation work reported in this paper (Lindgren, 1938).

\section{LOW, UNIFORM CONCENTRATION VERSUS HIGH-PEAK CONCENTRATION OF HCN}

In the major portion of the citrus fumigation in California, the hydrocyanic acid (which is in liquid form) is applied by means of a vaporizer that rapidly diffuses the gas within the tent. A high-peak concentration is reached within a few seconds after the gas is applied, followed by a rapid drop in concentration due mostly to tent leakage. There is some difference of opinion among fumigators as to whether a peak type of concentration has any advantage over a low and uniform type of concentration. "Interval shooting," or the introduction of the fumigant in two or more charges with a time interval between the applications, has been suggested as a possible substitute for the general practice of introducing the entire dosage of HCN at once. Cupples (1933) states :

.... there is some diversity of opinion as to the comparative toxicity toward scale of equal amounts of hydrocyanic acid used in the regular way and in interval shooting. Again the consensus of opinion seems to be that there is little to choose between the two methods, with any advantage lying on the side of the regular method.

In their investigations Pratt, Swain, and Eldred (1931) stated that:

... f for the most effective results the scale insects must be hit hard and quickly. .... This theory of high initial concentrations of HCN gas quickly and uniformly distributed throughout the tented enclosure has been substantiated by subsequent work in our laboratories, as well as by other investigators. In commercial work this theory is reduced to practice by applying the dose of HCN as a single charge. 


\section{Moore (1933) concluded:}

The type of concentration curve has no decided influence upon the kill providing there is a good distribution of gas. A low concentration built up and maintained and a quick high concentration rapidly leaking away gave similar results.

Rapid diffusion of gas is essential in red-scale fumigation, inasmuch as this insect, on exposure to sublethal concentrations of HCN, becomes stupefied and as a consequence becomes more difficult to kill. The tendency toward high, initial concentrations by the use of vaporized gas in citrus fumigation is probably due to the rapid and uniform distribution of gas throughout the tree, which eliminates the possibility of "protective stupefaction" (Lindgren, 1938, p. 213) that might occur if the $\mathrm{HCN}$ were allowed to diffuse slowly throughout the tree.

A uniform supply of both the resistant and the nonresistant red scale, reared from stock cultures in the insectary, was available for experimental purposes in determining the relative merits of a high-peak concentration and a low, uniform type of concentration on the two strains. A series of experiments was conducted with high-peak types of concentration using dosages of $4,8,10,12,14,16,18,20,22,24$, and 26 cc of HCN per unit under form tents of 8-unit size (approximately 800 cubic feet). The forms consisted of iron framework, which, when covered with 8-ounce-duck tents, approximated the shape of a small citrus tree. In these forms no foliage was present to interfere with the diffusion of the gas nor was sorption of $\mathrm{HCN}$ by the tree a factor. A dosage of 26 ce was not used on the nonresistant scales because of the high kills obtained with the lower dosages. Along with these tests were another group of experiments in a gastight fumatorium of 100-cubic-foot capacity with low, uniform concentration, using dosages of $1,2,3,4,5,6$, and 8 ec of HCN. Dosages of 6 and $8 \mathrm{ce}$ HCN were not used on the nonresistant red scale. In the high-peak type of concentration almost all the gas had leaked through the tent by the end of the 45 -minute fumigation period; whereas with the low, uniform type of concentration practically no gas was lost from the fumatorium during the 45-minute fumigation period. Both resistant and nonresistant adult female red scales 38 to 40 days old, reared on grapefruit under identical conditions in the insectary, were used in all the tests. The treatments which these infested fruits received before and after fumigation were similar, the only variable being the type of concentration the scales were exposed to during fumigation. Experiments conducted under the form tents were car-

\footnotetext{
${ }^{5} \mathrm{~A}$ unit in citrus fumigation is roughly 100 cubic feet for the average-sized tree. In a larger tree, a unit would be greater than 100 cubic feet, and in a small tree a unit would be less than 100 cubic feet, since the ratio of tent surface (through which the gas escapes) to volume is greater in a small tree than in a large one.
} 
ried on in August and September. Mortality counts were made 14 days after fumigation. Natural mortality was not taken into consideration since there was no appreciable mortality in the controls.

Samples of gas to determine the exact concentration of HCN were taken from the center of the tent and from the center of the fumatorium at $1,3,7,15,30$, and 45 minutes from the time fumigation began, and the mean average concentration in milligrams per liter $(\mathrm{mg} / \mathrm{l})$ was calculated from the results of the titrations. Diffusion of gas was rapid in both the tent and the gastight fumatorium, and the concentration was

TABLE 1

Results of Fumigation of Nonresistant Red Scale under a Form Tent with a High-Peak Concentration and in a Metal Fumatorium WITH A LOW, UNIFORM CONCENTRATION

(Exposure, 45 minutes)

\begin{tabular}{|c|c|c|c|c|c|c|c|}
\hline \multicolumn{4}{|c|}{$\begin{array}{l}\text { High-peak type of concentration } \\
\text { in an 8-unit form tent }\end{array}$} & \multicolumn{4}{|c|}{$\begin{array}{l}\text { Low, uniform type of concentration in a 100-cubic- } \\
\text { foot metal fumatorium }\end{array}$} \\
\hline $\begin{array}{l}\text { HCN } \\
\text { dosage }\end{array}$ & $\begin{array}{l}\text { Concen- } \\
\text { tration }\end{array}$ & $\begin{array}{l}\text { Number of } \\
\text { insects } \\
\text { examined }\end{array}$ & Mean kill & $\begin{array}{c}\mathrm{HCN} \\
\text { dosage }\end{array}$ & $\begin{array}{l}\text { Concen- } \\
\text { tration }\end{array}$ & $\begin{array}{l}\text { Number of } \\
\text { insects } \\
\text { examined }\end{array}$ & Mean kill \\
\hline $\begin{aligned} c c \\
4\end{aligned}$ & $\begin{array}{l}m g / l \\
0.299\end{array}$ & 12,441 & $\begin{array}{l}\text { per cent } \\
98.44\end{array}$ & $\begin{array}{l}c c \\
1\end{array}$ & $\begin{array}{l}m g / l \\
0.198\end{array}$ & 4,980 & $\begin{array}{l}\text { per cent } \\
94.93\end{array}$ \\
\hline 8 & 0.479 & 8,500 & 99.29 & 2 & 0.427 & 3,638 & 98.69 \\
\hline 10 & 0.534 & 5,550 & 99.63 & 3 & 0.528 & 4,850 & 99.43 \\
\hline 12 & 0.603 & 8,750 & 99.79 & 4 & 0.713 & 4,443 & 99.54 \\
\hline 14 & 0.728 & 4,200 & 99.84 & 5 & 0.817 & 3,368 & 99.85 \\
\hline 16 & 0.820 & 6,900 & 99.95 & & & & \\
\hline 18 & 0.913 & 5,475 & 100.00 & & & & \\
\hline 20 & 0.981 & 4,575 & 99.98 & & & & \\
\hline 22 & 1.209 & 1,650 & 99.94 & & & & \\
\hline 24 & 1.215 & 1,200 & 100.00 & & & & \\
\hline
\end{tabular}

built up in less than $1 / 2$ minute. Diffusion in the fumatorium was obtained with a built-in fan; the vaporizer diffused the gas rapidly and uniformly throughout the tent.

The results of fumigation with high-peak, and with low, uniform types of concentration are shown in table 1 for the nonresistant red scale and in table 2 for the resistant red scale. Exceptionally high kills of the nonresistant scale were obtained with all dosages tried, an 8-cc dosage giving a kill of 99.29 per cent and a 22-ce dosage a kill of 99.94 per cent, or an increase of only 0.65 per cent with almost triple the dosage. The kills obtained with the resistant red scale were not nearly so high as those with the nonresistant scale. The mortality of resistant scale obtained at the higher dosages was less than that of the nonresistant strain at the lower dosages. With an increase in dosage there is a gradual increase in kill of the resistant strain up to the higher concentrations 
of HCN, where the rate of increase in kill tends to slow down. As far as commercial fumigation is concerned, the differences in kill between the resistant and nonresistant strains are extremely important. At a dosage of 20 ec per unit-a dosage commonly used in citrus fumigation-it is observed from tables 1 and 2 that out of every 10,000 insects there would be 2 alive of the nonresistant females whereas 431 resistant females would be alive. If, as has been estimated, there are 500,000 live scales on a heavily infested tree and each female that survives the fumigation is able to produce from 50 to 150 young, it can be readily understood

\section{TABLE 2}

Results of Fumigation of Resistant Red Scale under a Form Tent with a HighPeak Concentration and in a Metal Fumatorium with A Low, UNIFORM CONCENTRATION

(Exposure, 45 minutes)

\begin{tabular}{c|c|c|c||c|c|c|c}
\hline \hline \multicolumn{3}{c||}{$\begin{array}{c}\text { High-peak type of concentration } \\
\text { in an 8-unit form tent }\end{array}$} & \multicolumn{2}{c}{ Low, uniform type of concentration in a 100-cubic- } \\
foot metal fumatorium
\end{tabular}

why groves infested with the resistant scale are fumigated once or twice a year, whereas those infested with the nonresistant scale are fumigated only once in two or three years.

Since it is difficult to make direct comparisons of the results in tables 1 and 2, calculated regression lines of the data are presented in figure 1. The calculations were made according to the methods of Bliss (1935). There is an advantage in kill in favor of the high-peak concentration both with the nonresistant and with the resistant red scale. The zones of error of the regression lines have been calculated to determine the accuracy of the concentration-mortality curve, using a $P$ value of 0.05 . The graphic zones of error are not included in the figure because the chart would become confusing, but the zone of error of the high-peak concentration just overlaps that of the low, uniform concentration with 
both the resistant and nonresistant red scale, which indicates that there is no significant difference between the two. Since the two series of fumigations, however, are close to being significantly different, under the conditions of these experiments the high-peak type of concentration, such as is obtained in field practice, has a probable advantage over the low, uniform type of concentration in the range of dosages tried. Even though the differences are small, the fumigation procedure that gives

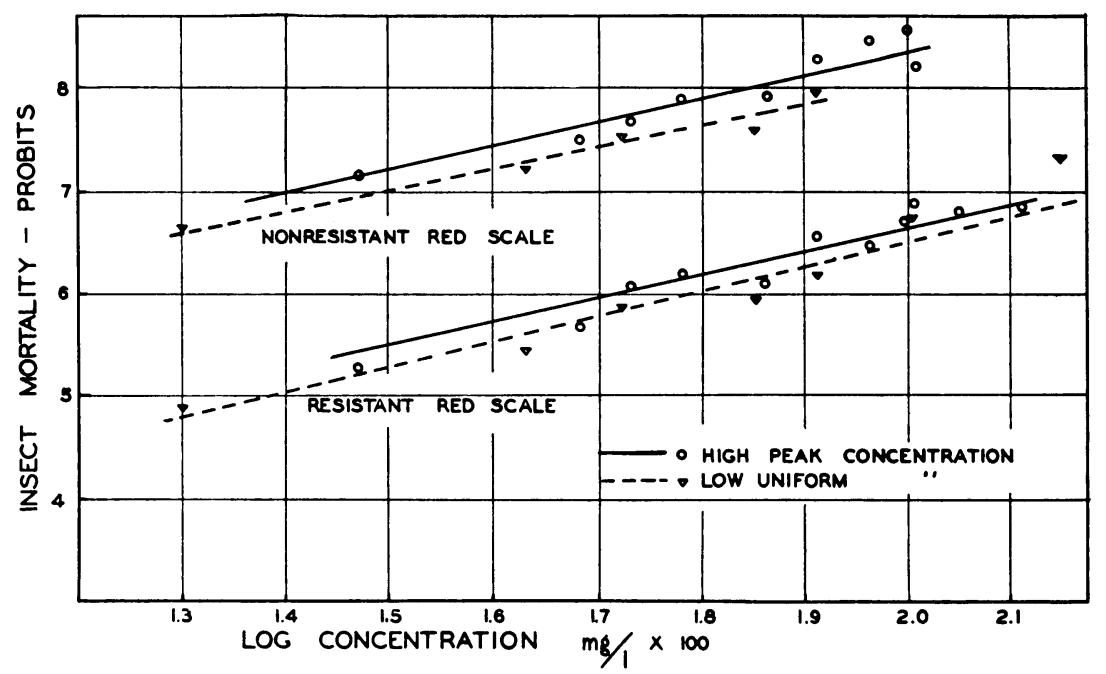

Fig. 1.-Results of fumigation of nonresistant and resistant red scale with a highpeak concentration and a low, uniform concentration of HCN. (Data from tables 1 and 2.)

the best possible control is the one to practice in the field, especially in red-scale control where the survival of a few more scales per tree may mean the difference between fumigating every year or every other year.

\section{DURATION OF EXPOSURE}

In field fumigation of citrus, each tree is given an exposure of 45 to 50 minutes. The liquid HCN is converted to gas under the tent by either an atomizer or a vaporizer. The latter heats the HCN and liberates the charge as a gas with considerable force. Both devices expose the insects almost immediately to the full charge of $\mathrm{HCN}$, but within a very short time the concentration of gas under the tent begins to drop, owing to leakage through the relatively coarse canvas. At the end of 45 minutes there is very little $\mathrm{HCN}$ under the tent. Actually at the end of 30 minutes the red scale has been exposed to 90 per cent of the gas to which it would have been exposed if the duration of the fumigation had been 45 minutes. 
Therefore, reducing the time by one third would result in a reduction of only one tenth in the amount of gas to which the insect would be exposed.

Swain (1918), in working with exposures of $30,45,60$, and 90 minutes on red seale, concluded that there is no advantage in an exposure of $11 / 2$ hours over that of a 45-minute exposure. He found, however, that a decidedly higher killing efficiency occurred in a 45 -minute than in a 30 minute exposure.

Kirkpatrick (1939) concluded from his investigations over a period of four years that both the red and the black seales could be satisfactorily controlled in most orchards in the coastal area with dosages and expossures that are much less than those often considered necessary, and that such satisfactory control may thus be obtained with reduced hazard to both young and mature fruit and at a materially lessened cost to the grower. In many cases he used dosages as low as 9 ec and exposures of 25 or 30 minutes, with excellent results on both the black and the red scales.

Procedure.-A series of experiments was conducted to determine the relative value of 15-, 30-, and 45-minute exposures in the fumigation of red scale, since a study of the gas concentrations under the tent indicated that the insects were exposed to 90 per cent of the gas in the first 30 minutes of the fumigation. These experiments were carried on under two 8-unit form tents of the same size and shape. Both resistant and nonresistant mature female red scales, 38 to 40 days old, reared on grapefruits under identical conditions in the insectary, were used in the experiments. Three wire baskets of fruit with nonresistant red scale and three wire baskets of fruit with resistant red scale were hung in each tent as close to the center of the tent as possible in relation to top and bottom and to the sides. Four of the baskets in each tent were attached to a heavy cord which passed over a pulley to the outside of the tent, where, by a simple manipulation, two baskets of infested fruit (one basket containing resistant and the other containing nonresistant red-scaleinfested fruit) could be removed from the tent at the end of 15 minutes, with the loss of very little or no HCN gas. At the end of 30 minutes, two more baskets of infested fruit were removed; and at the end of 45 minutes, the canvas tent was folded back from the form and the remaining two baskets of fruit were removed. In this manner results were obtained for 15-, 30-, and 45-minute exposures from one fumigation ; and thereby, those insects receiving the 45-minute fumigation were exposed to the same concentration of gas as the insects exposed to the first 15 or 30 minutes plus the additional 30 or 15 minutes.

The fumigations were conducted in the evening, between 7 p.m. and 


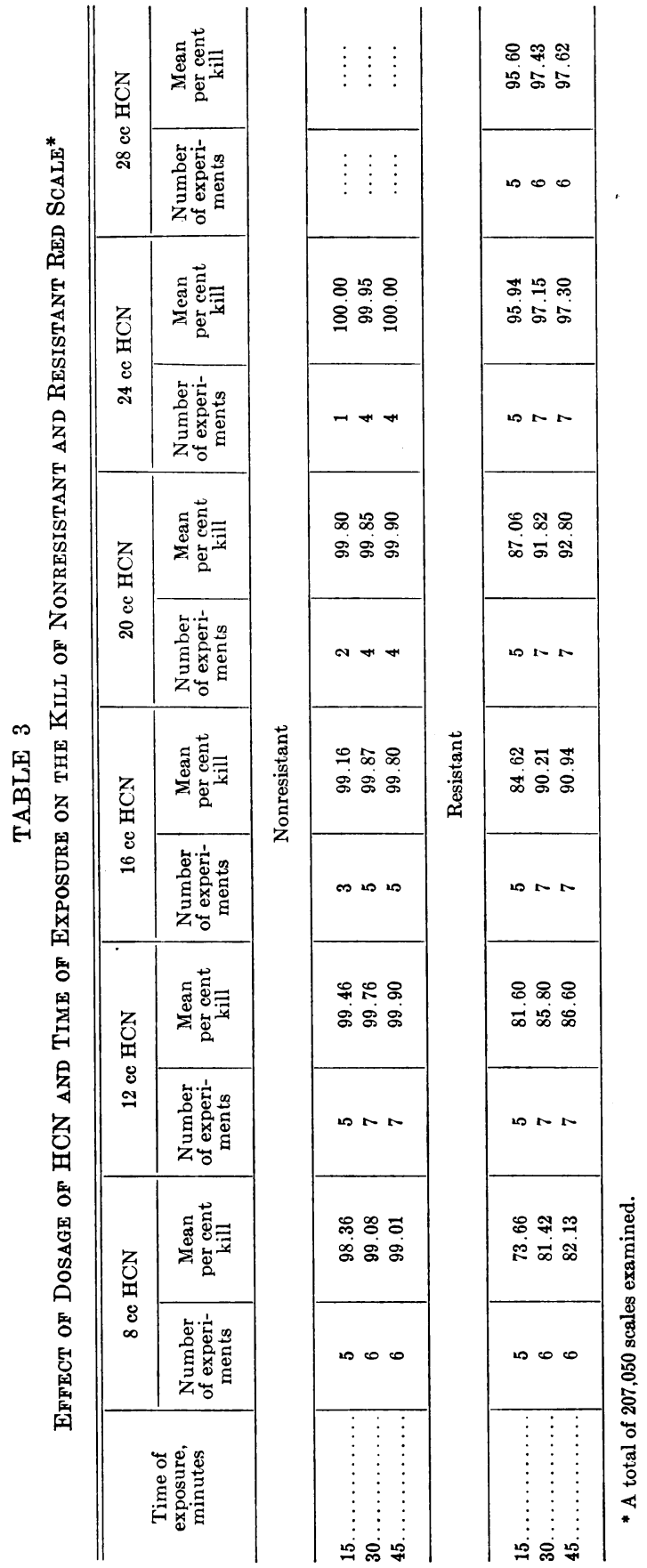


10 p.m., beginning just after the sun had set, and there was very little movement of air. Temperature and humidity records were kept of all fumigations. Samples of gas for titration were taken from the center of the form tents at $1,4,7,15,30$, and 45 minutes from the time the fumigation began. The dosages used were $8,12,16,20,24$, and 28 cc of HCN per unit. Six experiments were carried on in any one evening, using each of the six different dosages. The dosages were alternated from evening to evening in relation to time so that no given dosage was tried at the same time each evening.

Discussion of Results.-The experiments with nonresistant red scale show no significant difference between exposures of 15,30 , and 45 minutes, at the dosages tried (table 3 ). In every case the kills were very high, too high for experimental purposes. If the dosages tried had been lowered for the nonresistant red scale, a difference between exposures of 15 and 30 minutes might have been discernible. No dosages lower than $16 \mathrm{cc}$, however, are used in the field, and it did not seem worth while to go below a dosage of $8 \mathrm{cc}$ of $\mathrm{HCN}$ and an exposure of 15 minutes, since this dosage and exposure is much less than that used commercially.

The results with resistant red scale show, in most cases, a significant difference in kill between the means of the exposures of 15 minutes and 30 minutes, but no significant difference between the means of the exposures of 30 minutes and 45 minutes. At the lower dosages of $\mathrm{HCN}$, the differences between the means of the 15-minute and 30-minute exposures are rather large; but at the higher dosages, these differences become less marked, as is expected. A dosage of $20 \mathrm{ec}$ of $\mathrm{HCN}$ per unit and an exposure of 45 minutes resulted in a kill of only 92.80 per cent of the adult females, which is not satisfactory from a commercial viewpoint. Since the red scales in the second molt and gray-adult stage (p. 507-9) are much more difficult to kill, dosages of 20 ce per unit would not keep a grove commercially clean for a satisfactory length of time.

In some of the areas in California where the resistant red scales occur, dosages of $28 \mathrm{cc}$ of HCN per unit are used on lemons and 26 ce on oranges, and fumigation is being carried on once and sometimes twice a year for the control of red scale. If it were possible to classify accurately infestations in citrus groves in California as resistant or nonresistant red scale, the cost of controlling the nonresistant strain could be reduced by the use of lower dosages and shorter exposures. Also, control of the resistant strain might be considerably improved by the use of the highest possible dosages of $\mathrm{HCN}$ without injury to the tree. The resistant red scales are better able to survive a dosage of 28 ce than the nonresistant red scales an 8-ce dosage (or even a 4-cc dosage, as a few preliminary experiments with this dosage indicate). A kill of 98.36 per cent 
of the nonresistant red scale was obtained with a dosage of $8 \mathrm{cc}$ and an exposure of 15 minutes, whereas a kill of 97.62 per cent of the resistant red scale was obtained with 28 ec of HCN per unit and an exposure of 45 minutes.

Although it would be difficult to classify grove infestations in certain areas according to resistance, there are large areas in southern California in which the red scales are apparently readily controlled by relatively low dosages of $\mathrm{HCN}$, and other areas in which the resistant strain predominates. In the latter areas all degrees of resistance may be found, from scales that are difficult to kill to those that are easily killed. That is, in some groves there may exist practically a pure strain of the nonresistant red scale; in other groves may be found practically a pure strain of the resistant type; whereas in still other groves a mixture of the two strains is found, which is the result of crosses between the resistant and the nonresistant strain. Dickson (1941) demonstrated that the two strains of scale will interbreed, the $\mathrm{F}_{1}$ females falling about halfway between their parents in susceptibility to $\mathrm{HCN}$ fumigation.

Table 3 indicates that in almost every case (the two exceptions each differing by only 0.07 per cent) the 45 -minute exposure to $\mathrm{HCN}$ is slightly more efficient in killing the nonresistant and the resistant red scale than the 30-minute exposure. Even though the differences are not significant statistically, the trend toward better control of the red scale at the longer exposure is evident. Before drawing any conclusion or making any recommendations regarding practical field fumigation, attention is directed to the fact that this series of experiments was carried on in form tents under ideal conditions, and the utmost care was taken with each fumigation.

\section{EFFECT OF PREFUMIGATION AND PRECONDITIONING}

Earlier research by several workers has shown that more red scales will survive a regular HCN fumigation if they are first exposed to a sublethal dose of it (Gray and Kirkpatrick, 1929 ; Pratt, Swain, and Eldred, 1931; Lindgren, 1938). Quayle and Rohrbaugh (1934) demonstrated that red scales are more susceptible to HCN if they have been preconditioned at a relatively low temperature $\left(50^{\circ} \mathrm{F}\right)$ for several hours before the fumigation. They found that temperatures between $50^{\circ}$ and $90^{\circ}$ $\mathrm{F}$ during the actual fumigation period made no significant difference in the kill of red scale, probably because there was little change in the temperature of the fruit and the scale insects closely attached to it during the fumigation period, but temperatures to which the fruits were subjected previous to the fumigation had a marked effect on the fumigation results. Peters (1936) found that the resistance of the gran- 
ary weevil to $\mathrm{HCN}$ is lowered at a temperature of $5^{\circ} \mathrm{C}$, owing to the loss of the ability to effect a defense reaction which occurs at higher temperatures. A similar situation perhaps occurs with the red scale, and if this so-called "defense reaction" is lost at low temperatures, no protective stupefaction should occur at these low temperatures.

Quayle and Rohrbaugh (1934) found no significant difference was indicated concerning the effect of humidity within a range of from 50 to 80 per cent on fumigation results on the red scale. Relative humidities of 85 to 100 per cent gave a decrease in kill as compared with low relative humidities of from 27 to 40 per cent.

Laboratory experiments have indicated an increased kill of red scale when infested fruits are covered with a thin film of moisture during the

TABLE 4

Mean Percentage of Kill of Red Scale Fumigated after Being Preconditioned AT $50^{\circ} \mathrm{F}$ For VARYing PeRIOdS*

(Fumigation at $75^{\circ} \mathrm{F}$ )

\begin{tabular}{|c|c|c|c|c|c|c|c|}
\hline \multirow{2}{*}{$\begin{array}{l}\text { Type of } \\
\text { red scale }\end{array}$} & \multirow{2}{*}{$\begin{array}{c}\text { Concentra- } \\
\text { tion } \\
\text { of } \mathrm{HCN}\end{array}$} & \multirow{2}{*}{$\begin{array}{c}\text { Kill of scale } \\
\text { not pre- } \\
\text { conditioned }\end{array}$} & \multicolumn{5}{|c|}{ Kill of scale after various preconditioning periods } \\
\hline & & & 30 minutes & 1 hour & 2 hours & 3 hours & 4 hours \\
\hline $\begin{array}{l}\text { Nonresistant... } \\
\text { Resistant..... }\end{array}$ & $\begin{array}{l}m g / l \\
0.205 \\
0.378\end{array}$ & $\begin{array}{c}\text { per cent } \\
\quad 97.5 \\
83.4\end{array}$ & $\begin{array}{c}\text { per cent } \\
98.7 \\
90.9\end{array}$ & $\begin{array}{c}\text { per cent } \\
99.4 \\
95.4\end{array}$ & $\begin{array}{c}\text { per cent } \\
99.4 \\
97.0\end{array}$ & $\begin{array}{c}\text { per cent } \\
\quad 995 \\
97.5\end{array}$ & $\begin{array}{c}\text { per cent } \\
99.9 \\
96.8\end{array}$ \\
\hline
\end{tabular}

* A total of 45,500 insects examined.

fumigation, such as would be found in the field under conditions of high humidities.

Duration of Preconditioning Period.-Several preliminary experiments were made to determine the effect of preconditioning periods of varying lengths at $50^{\circ} \mathrm{F}$ on the kill of both the resistant and nonresistant red scale. The temperature at the time of the fumigation was $75^{\circ}$. The results, as shown in table 4, are similar to those obtained by Quayle and Rohrbaugh (1934). Three hours of preconditioning at $50^{\circ}$ seemed sufficient to obtain the full effect on the fumigation results.

Experimental Procedure.-Two series of experiments were conducted to determine what effect preconditioning at high and low temperatures would have on the prefumigation ${ }^{6}$ of resistant and nonresistant red scale with low dosages of $\mathrm{HCN}$. Adult female resistant and nonresistant red scales, 38 to 40 days old, reared on grapefruit in the insectary, were used in all the experiments. Two groups of fruit, one infested with resistant scale and another with nonresistant scale, were divided into four lots each. The first lot of each group was held at $75^{\circ} \mathrm{F}$ before fumigation;

- Prefumigation is the exposure of insects to a low dosage of HCN for 5 minutes before the regular fumigation. 
the second lot was held at $75^{\circ}$ and prefumigated with a low dosage of HCN before the regular fumigation; the third lot was held at $50^{\circ}$ for 3 to 4 hours before fumigation, without prefumigation; and the fourth lot was held at $50^{\circ}$ for 3 to 4 hours and prefumigated with a low dosage of $\mathrm{HCN}$ before the regular fumigation.

In a second series of similar experiments a preconditioning temperature of $90^{\circ} \mathrm{F}$ was used instead of that of $50^{\circ}$. In both sets of experiments the resistant red scales were prefumigated immediately before the regular fumigation, whereas in the case of the nonresistant scale there was an interval of 1 hour between the sublethal dose of $\mathrm{HCN}$ and the regular fumigation, since it had been shown that some time must elapse before the sublethal dose becomes effective on the nonresistant red scale (Lindgren, 1938). The stupefying, or sublethal, concentration of gas used was $0.121 \mathrm{mg} \mathrm{HCN}$ per liter, with an exposure of 5 minutes.

All fumigations were carried on at a temperature of $75^{\circ} \mathrm{F}$ and at relative humidities ranging from 40 to 60 per cent with an exposure of 40 minutes. During the fumigation the fruit preconditioned at $50^{\circ}$ tended to rise in temperature, whereas the fruit preconditioned at $90^{\circ}$ tended to drop in temperature. Infested fruits were held at $70^{\circ}$ to $74^{\circ}$ after fumigation and the counts made at the end of 14 days. A total of 233,965 scales were counted in this series of experiments. Infested fruits held as checks at $50^{\circ}$ and $90^{\circ}$ for as long as 8 hours showed no more natural mortality than did insects held at $75^{\circ}$, which averaged 3 to 4 per cent.

Three dosages of HCN gas were used in each series. The four lots subjected to a given dosage in each group in each series were fumigated together and therefore the mean average concentration was exactly the same for the four. This makes it possible to calculate the least significant mean differences at the 5 per cent level (Snedecor, 1937) as a basis of comparison.

Results with Resistant Red Scale.-The comparison of kills for the two series of fumigation experiments with resistant red scale, in which the preconditioning temperatures for 3 to 4 hours were $50^{\circ}$ and $90^{\circ} \mathrm{F}$, is given in table 5 .

Results for series 1 (table 5) indicate that without preconditioning, the percentage kill of resistant red scale by fumigation was lower with prefumigation than without it, at all HCN dosages. Preconditioning at $50^{\circ} \mathrm{F}$ without prefumigation increased the kill as compared with lots not preconditioned (held at $75^{\circ}$ ). Prefumigation following this preconditioning treatment decreased the kill, and in some cases even gave a lower kill than the lots with no preconditioning and no prefumigation; it was still somewhat higher, however, than that obtained with prefumi- 
gation but without preconditioning. These responses indicate that preconditioning resistant red scale at $50^{\circ}$ does not entirely overcome the effects of protective stupefaction.

Series 2 of table 5 gives the results of fumigation experiments with a preconditioning temperature of $90^{\circ} \mathrm{F}$. The percentage kill of the lots of resistant red scales not preconditioned (held at $75^{\circ}$ ) in series 2 should be similar to the corresponding lots in series 1 , since the insects received similar fumigation treatments. The figures agree fairly well, the greatest difference between any two is 2.03 per cent. Scales precon-

\section{TABLE 5}

Mean Percentage of Kill of Resistant Red Scale by Fumigation WITH HCN AFTER VARIOUS PRETREatments*

(Fumigation at $75^{\circ} \mathrm{F}$, humidity $40-60$ per cent, exposure 40 minutes)

\begin{tabular}{|c|c|c|c|c|c|c|}
\hline \multirow{2}{*}{ Treatment } & \multicolumn{3}{|c|}{$\begin{array}{l}\text { Series 1, preconditioning temper- } \\
\text { ature (where used) } 50^{\circ} \mathrm{F}\end{array}$} & \multicolumn{3}{|c|}{$\begin{array}{l}\text { Series 2, preconditioning temper- } \\
\text { ature (where used) } 90^{\circ} \mathrm{F}\end{array}$} \\
\hline & $\begin{array}{c}0.380 \\
\text { mg HCN } \\
\text { per liter }\end{array}$ & $\begin{array}{c}0.775 \\
\text { mg HCN } \\
\text { per liter }\end{array}$ & $\begin{array}{c}1.036 \\
\text { mg HCN } \\
\text { per liter }\end{array}$ & $\begin{array}{c}0.372 \\
\text { mg HCN } \\
\text { per liter }\end{array}$ & $\begin{array}{c}0.767 \\
\text { mg HCN } \\
\text { per liter }\end{array}$ & $\begin{array}{c}1.028 \\
\text { mg HCN } \\
\text { per liter }\end{array}$ \\
\hline $\begin{array}{l}\text { Not preconditioned, } \uparrow \text { not pre- } \\
\text { fumigated } \ldots \ldots \ldots \ldots \ldots \ldots \ldots \ldots\end{array}$ & $\begin{array}{l}\text { per cent } \\
80.97\end{array}$ & $\begin{array}{c}\text { per cent } \\
92.87\end{array}$ & $\begin{array}{c}\text { per cent } \\
98.91\end{array}$ & $\begin{array}{c}\text { per cent } \\
83.00\end{array}$ & $\begin{array}{c}\text { per cent } \\
94.67\end{array}$ & $\begin{array}{c}\text { per cent } \\
97.58\end{array}$ \\
\hline $\begin{array}{l}\text { Not preconditioned, } t \text { prefumi- } \\
\text { gated............................ }\end{array}$ & 72.32 & 81.54 & 87.65 & 73.58 & 83.42 & 89.44 \\
\hline $\begin{array}{l}\text { Preconditioned, } \ddagger \text { not prefumi- } \\
\text { gated........................... }\end{array}$ & 95.87 & 98.18 & 99.80 & 79.20 & 93.94 & 98.85 \\
\hline Preconditioned, $\ddagger$ prefumigated... & 89.58 & 93.06 & 95.06 & 75.04 & 85.08 & 90.00 \\
\hline Least significant difference........ & 3.9 & 4.0 & 8.6 & 4.1 & 3.6 & 9.0 \\
\hline
\end{tabular}

* A total of 116,895 insects examined.

$\dagger$ Held at $75^{\circ} \mathrm{F}$ before fumigation or prefumigation.

$\ddagger$ Preconditioning time 3 to 4 hours; temperature $50^{\circ}$ or $90^{\circ} \mathrm{F}$ (see series no.).

ditioned at $90^{\circ}$ were no more difficult to kill than those not preconditioned, but at both $90^{\circ}$ and $75^{\circ}$ the percentage kill was lower with prefumigation than without it.

A study of table 5 indicates that a much higher kill was obtained from a given fumigation when the resistant red scales had been preconditioned at $50^{\circ} \mathrm{F}$. In field work the best results from fumigation are obtained during the winter months, owing probably to the following factors operating together: (1) red scales are more susceptible to HCN fumigation at low temperature; (2) red scales are rather susceptible to $\mathrm{HCN}$ fumigation in the adult stage, which are present in the greatest numbers in comparison to the other stages in the winter months; (3) higher dosages are usually employed in the winter months.

Results with Nonresistant Red Scale.-In a comparable set of fumi- 
gation experiments with the nonresistant red scale, the results from prefumigation and preconditioning were very similar (table 6 ).

Results for series 1 (table 6) indicate that without preconditioning, the percentage kill of nonresistant red scale was lower with prefumigation 1 hour before fumigation than without it, at all dosages. The percentage kill for lots preconditioned at $50^{\circ} \mathrm{F}$ without prefumigation increased as compared with lots not preconditioned (held at $75^{\circ}$ ). Though the differences are not significant owing to the high kills obtained, the trend is toward better control. When the two lots that were precondi-

\section{TABLE 6}

Mean Percentage of Kill of Nonresistant Red Scale by Fumigation With HCN AFTER VARIOUS PRETREaTMENTS*

(Fumigation at $75^{\circ} \mathrm{F}$, humidity $40-60$ per cent, exposure 40 minutes)

\begin{tabular}{|c|c|c|c|c|c|c|}
\hline \multirow{2}{*}{ Treatment } & \multicolumn{3}{|c|}{$\begin{array}{l}\text { Series 1, preconditioning temper- } \\
\text { ature (where used) } 50^{\circ} \mathrm{F}\end{array}$} & \multicolumn{3}{|c|}{$\begin{array}{l}\text { Series 2, preconditioning temper- } \\
\text { ature (where used) } 90^{\circ} \mathrm{F}\end{array}$} \\
\hline & $\underset{\text { per liter }}{0.212}$ & $\begin{array}{c}0.378 \\
\text { per HCN } \\
\text { per liter }\end{array}$ & $\underset{\text { per liter }}{0.552}$ & $\begin{array}{c}0.207 \\
\text { mg HCN } \\
\text { per liter }\end{array}$ & $\begin{array}{c}0.385 \\
\text { mer HCN } \\
\text { per liter }\end{array}$ & $\begin{array}{c}0.574 \\
\text { mg HCN } \\
\text { per liter }\end{array}$ \\
\hline $\begin{array}{l}\text { Not preconditioned, } \nmid \text { not pre- } \\
\text { fumigated } \ldots \ldots \ldots \ldots \ldots \ldots \ldots \ldots\end{array}$ & $\begin{array}{c}\text { per cent } \\
97.97\end{array}$ & $\begin{array}{c}\text { per cent } \\
99.07\end{array}$ & $\begin{array}{c}\text { per cent } \\
99.76\end{array}$ & $\begin{array}{c}\text { per cent } \\
96.76\end{array}$ & $\begin{array}{c}\text { per cent } \\
99.62\end{array}$ & $\begin{array}{c}\text { per cent } \\
99.93\end{array}$ \\
\hline $\begin{array}{c}\text { Not preconditioned, } \downarrow \text { prefumi- } \\
\text { gated } \downarrow \ldots \ldots \ldots \ldots \ldots \ldots \ldots \ldots\end{array}$ & 77.47 & 88.49 & 92.06 & 75.89 & 85.82 & 92.29 \\
\hline $\begin{array}{l}\text { Preconditioned, I not prefumi- } \\
\text { gated } \ldots \ldots \ldots \ldots \ldots \ldots \ldots \ldots\end{array}$ & 99.62 & 100.00 & 99.98 & 89.54 & 97.35 & 99.47 \\
\hline Preconditioned, $\{$ prefumigated $\ddagger$. & 99.73 & 99.77 & 99.88 & 57.96 & 78.97 & 93.42 \\
\hline Least significant difference..... & 4.8 & 3.5 & 1.8 & 4.1 & 4.2 & 8.8 \\
\hline
\end{tabular}

* A total of 117,070 insects examined.

$\dagger$ Held at $75^{\circ} \mathrm{F}$ before fumigation or prefumigation.

$\ddagger$ A 1-hour interval between prefumigation and regular fumigation.

I Preconditioning time 3 to 4 hours; temperature $50^{\circ}$ or $90^{\circ} \mathrm{F}$ (see series no.).

tioned are compared, prefumigation appeared to have no effect, probably because no protective stupefaction occurred at the dosages of HCN used; the percentage kill was higher, however, than that obtained with prefumigation but without preconditioning.

Series 2 of table 6 gives the results of fumigation experiments with a preconditioning temperature of $90^{\circ} \mathrm{F}$. The percentage kill of the lots of nonresistant scales not preconditioned in series 2 is found to agree fairly well with the corresponding lots in series 1 , since the treatments were similar in both cases. Preconditioning at $90^{\circ}$ without prefumigation lowered the kill as compared with groups not preconditioned and not prefumigated. At the two lower concentrations (0.207 and 0.385 mg HCN per liter) preconditioning plus prefumigation gave the lowest percentage of kill of the four treatments; whereas, with a concentration 
of $0.574 \mathrm{mg} \mathrm{HCN}$ per liter, there was no significant difference between the lot which was prefumigated only and that which was both preconditioned and prefumigated.

In comparing the resistant and nonresistant red scale, preconditioning seems to have a greater effect on the latter than on the former, since with the nonresistant strain preconditioning at $50^{\circ} \mathrm{F}$ entirely overcame the effects of protective stupefaction from sublethal doses of $\mathrm{HCN}$, and preconditioning at $90^{\circ}$ tended to exaggerate the effects of prefumigation. Nonresistant red scales not preconditioned but prefumigated with a low dosage of $\mathrm{HCN}$ and fumigated with $0.552 \mathrm{mg} \mathrm{HCN}$ per liter are more difficult to kill (92.06 per cent kill) than the resistant red scales preconditioned at $50^{\circ}$ but not prefumigated and fumigated with 0.380 mg HCN per liter (95.87 per cent kill).

\section{FUMIGATION OF RED SCALE OF VARIOUS AGES}

In evaluating California-red-scale-fumigation results, usually the adult insect has been considered, whereas very little or no attention has been paid to the other stages ${ }^{7}$ in the life cycle. But over twenty years ago, Quayle (1920) had found red scale in the second molt to be the most resistant to HCN. He states :

On account of the difference in resistance at different periods in the development of the scale, it would be expected that the best fumigation results would be secured at a season when there are the fewest numbers in these resistant stages, and we have found such to be the case.

Moore (1934) in a series of field experiments determined the relative susceptibility of various stages of the red scale to fumigation with HCN. He found the second molt, end of the second molt, and early gray adult to be the most resistant of the stages tried ; and of these three the end of the second molt was the most resistant. But he concludes : "In fumigation where results are poor, survivors occur in all stages of development not merely in the second molt."

In field fumigation under practical conditions, all ages of the red scale are usually present, from the young crawler to the adult insect. The abundance of each of the various stages present in the field varies from one season of the year to another. Generally the proportion of adult females to the other stages is greatest in the winter and spring; the proportion of red scale in the first instar is greatest in the early summer; whereas the proportion of scales in the second instar soon equals that in the first instar, owing to the fact that the adult female produces young over a long period.

\footnotetext{
7 The term "stage" is used to designate any definite period in the development of an insect (de la Torre-Bueno, 1937). It may or may not be synonymous with the term "instar." In the case of the red scale we recognize more stages than there are instars. (See p. 506.)
} 
If there is a preponderance of certain stages of red scale at certain seasons of the year, it is desirable to know what stages are easiest to kill by fumigation with $\mathrm{HCN}$, and, if possible, synchronize the time of fumigation with the presence of the greatest number of the most susceptible stage. Therefore, a series of laboratory experiments was conducted with red scale on grapefruit to determine the relative susceptibility of the various stages of both the resistant and nonresistant strains to HCN.

Earlier in this work, before the fumigation of the various stages was studied, a series of experiments was conducted on young crawlers fumigated before any of them had time to settle. These experiments are of interest for two reasons : first, to show the susceptibility of the crawlers (without a scale covering) relative to that of the other stages, and second, to determine whether the motile young of the two strains of red scale varied in their resistance to HCN. Moore (1933) has stated that resistance might be due to the scale covering.

Red-scale crawlers were very easy to kill in comparison to the other stages of development. In a total of five separate fumigations with a concentration of $0.115 \mathrm{mg} \mathrm{HCN}$ per liter for 20 minutes, 1,354 of the resistant crawlers survived and settled, whereas only 11 of the nonresistant crawlers survived and settled out of a total of 2,000 or more crawlers to begin with for each strain. This indicates that the same resistance to $\mathrm{HCN}$ exists in the scale crawler as in the adult insect, as would be expected in a genetically borne characteristic (Dickson, 1941).

Since grapefruits were being infested with young red-scale crawlers each day, it was a simple matter to obtain red scale of any age from 1 day to 38 days old (mature females) or older. In the fumigation of red scales that had settled, seven different stages were used and were fumigated all at the same time. The ages and stages of insects reared at $80^{\circ}$ $\mathrm{F}$ and 80 per cent relative humidity were as follows :

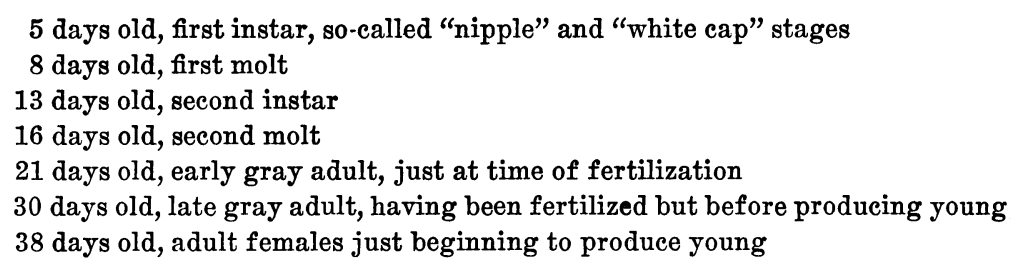

As it is difficult to distinguish between the male and female red scales before the second molt, both sexes were counted at the earlier ages-that is, those 5, 8, and 13 days old-but in many instances the survivors of a fumigation were allowed to develop so that the relative abundance of males and females might be determined. At these earlier ages the sexes survived a fumigation in about equal numbers. Only females were con- 
sidered from the second molt on, since the males become mature at 20 to 22 days old at $80^{\circ} \mathrm{F}$ and emerge from under the scale covering.

All seven age categories were fumigated at one time; and usually four fumigations, using the various dosages, were made on the same day. The data on the fumigations of the various stages of the resistant and nonresistant red scale are given in table 7 and are shown graphically in figures 2 and 3.

The nonresistant red scales (table 7 and fig. 2) are most resistant to $\mathrm{HCN}$ in the early-gray-adult stage at about the time the females are

TABLE 7

Results of Tests with Various Concentrations of HCN in Fumigating Different Stages of Nonresistant and Resistant Red Scale

(Exposure, 40 minutes)

\begin{tabular}{|c|c|c|c|c|c|c|c|c|}
\hline \multirow{3}{*}{ Stages } & \multicolumn{4}{|c|}{ Nonresistant } & \multicolumn{4}{|c|}{ Resistant } \\
\hline & \multicolumn{2}{|c|}{$\begin{array}{l}0.204 \mathrm{mg} \mathrm{HCN} \\
\text { per liter }\end{array}$} & \multicolumn{2}{|c|}{$\begin{array}{c}0.371 \mathrm{mg} H C N \\
\text { per liter }\end{array}$} & \multicolumn{2}{|c|}{$\begin{array}{l}0.377 \mathrm{mg} \mathrm{HCN} \\
\text { per liter }\end{array}$} & \multicolumn{2}{|c|}{$\begin{array}{l}0.756 \mathrm{mg} \mathrm{HCN} \\
\text { per liter }\end{array}$} \\
\hline & $\begin{array}{c}\text { Total } \\
\text { scales } \\
\text { counted }\end{array}$ & $\begin{array}{c}\text { Mean } \\
\text { per cent } \\
\text { kill }^{*}\end{array}$ & $\begin{array}{c}\text { Total } \\
\text { scales } \\
\text { counted }\end{array}$ & $\begin{array}{c}\text { Mean } \\
\text { per cent } \\
\text { kill* }^{*}\end{array}$ & $\begin{array}{c}\text { Total } \\
\text { scales } \\
\text { counted }\end{array}$ & $\begin{array}{c}\text { Mean } \\
\text { per cent } \\
\text { kill* }\end{array}$ & $\begin{array}{c}\text { Total } \\
\text { scales } \\
\text { counted }\end{array}$ & $\begin{array}{c}\text { Mean } \\
\text { per cent } \\
\text { kill }\end{array}$ \\
\hline $\begin{array}{l}\text { Nipple stage, first instar, } \\
5 \text { days old } \ldots \ldots \ldots \ldots \ldots \ldots\end{array}$ & 3,353 & 98.34 & 4,000 & 99.63 & 3,628 & 93.95 & 3,522 & 97.36 \\
\hline First molt, 8 days old..... & 3,990 & 95.61 & 4,015 & 97.20 & 4,100 & 82.38 & 3,194 & 95.85 \\
\hline Second instar, 13 days old & 4,554 & 92.12 & 3,281 & 97.11 & 4,272 & 68.91 & 3,373 & 91.40 \\
\hline $\begin{array}{l}\text { Second molt, } 16 \text { days old.. } \\
\text { Early gray adult, } 21\end{array}$ & 4,450 & 90.95 & 4,350 & 97.20 & 4,192 & 41.51 & 4,750 & 76.91 \\
\hline $\begin{array}{l}\text { days old . ............. } \\
\text { Late gray adult, } 30 \text { days }\end{array}$ & 4,280 & 79.82 & 4,100 & 92.09 & 3,700 & 47.81 & 4,350 & 88.37 \\
\hline 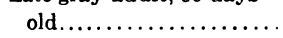 & 3,300 & 97.68 & 2,500 & 98.84 & 2,500 & 81.00 & 2,500 & 92.40 \\
\hline Adult female, 38 days old. & 4,050 & 97.20 & 4,300 & 99.47 & 4,010 & 81.74 & 3,950 & 94.79 \\
\hline
\end{tabular}

* Average of eight separate experiments.

being fertilized. Those insects in the first instar (5 days old), the late gray adults, and mature females are the most susceptible to fumigation with $\mathrm{HCN}$ gas. After 21 days, the nonresistant scales become very much easier to kill by $\mathrm{HCN}$, as shown by the sudden increase in mortality at this time. With a concentration of $0.204 \mathrm{mg} \mathrm{HCN}$ per liter, a kill of 79.82 per cent of 21-day-old red scale was obtained, while with the same concentration a kill of 97.68 per cent was obtained with insects 30 days old. A relation, similar though not so marked, was procured with a concentration of $0.371 \mathrm{mg} \mathrm{HCN}$ per liter.

Stages of red scale in which the waxy covering is firmly attached to the insect are not necessarily those most resistant to fumigation. The scale covering is firmly attached to the insect during the first and second molts and after fertilization, which at a constant temperature of $80^{\circ} \mathrm{F}$ 
takes place at the age of 21 days or soon thereafter. At 21 days, just before or during fertilization, the waxy covering is not firmly attached to the insect; and when the covering is lifted, it is found to be entirely

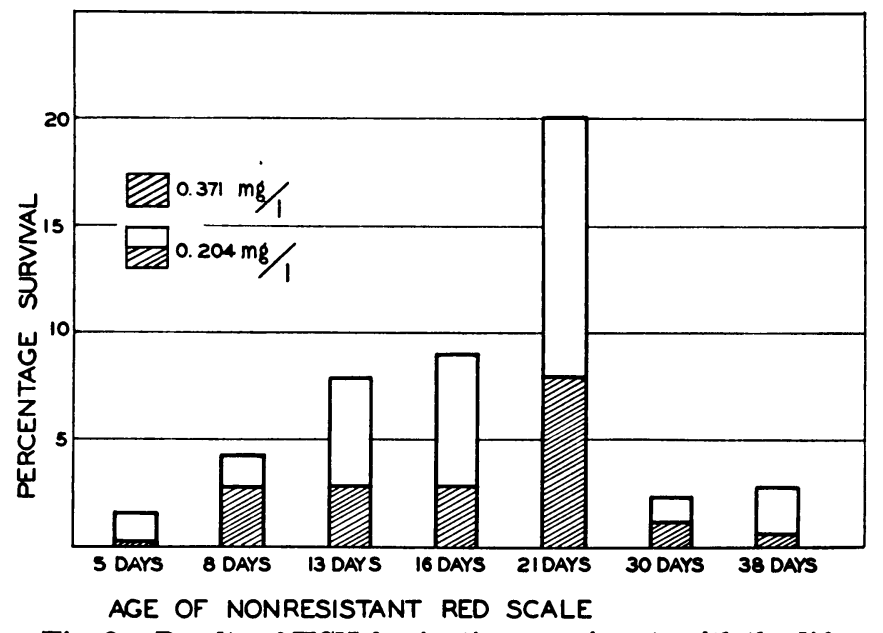

Fig. 2.-Results of HCN fumigation experiments with the different ages of nonresistant red scale. (Data from table 7.)

free from the insect and fits rather loosely over the body. But with the nonresistant strain, of the stages tested, these early gray adults are the most difficult to kill with $\mathrm{HCN}$ gas. On the other hand, the scale

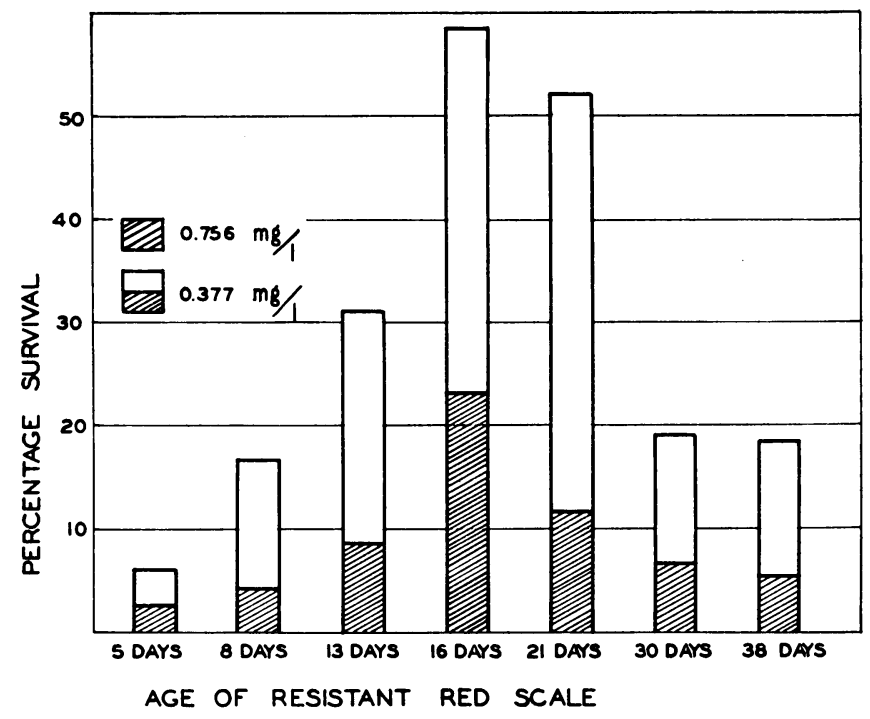

Fig. 3.-Results of HCN fumigation experiments with different ages of resistant red scale. (Data from table 7.) 
covering of the late gray adult and mature female is firmly attached to the insect, yet these stages are more susceptible to $\mathrm{HCN}$ fumigation. Therefore, in the nonresistant strain the firmness by which the scale covering is attached to the female scale is not correlated with resistance of the red scale to fumigation.

Of the stages of the resistant red scale tested, the most resistant to HCN were first, the second molt, and second, the early-gray-adult stage, whereas the 5-day-old scales were the most susceptible (table 7 and fig. 3). Here again there is a marked increase in the susceptibility of the scale to HCN from the early gray adult to the late gray adult. In the case of the resistant red scale, the second molt (one of the stages in which the scale covering is firmly attached to the insect) is the most difficult to kill by fumigation with $\mathrm{HCN}$.

In studying table 7 as a whole it will be noticed that $0.204 \mathrm{mg} \mathrm{HCN}$ per liter gave a better kill of all stages of the nonresistant strain tested than was obtained with $0.377 \mathrm{mg} \mathrm{HCN}$ per liter on the same stages of the resistant strain. This also holds true with a concentration of 0.371 $\mathrm{mg} \mathrm{HCN}$ per liter on the nonresistant red scale as against $0.756 \mathrm{mg} \mathrm{HCN}$ per liter on the resistant strain. Five of the seven stages of resistant red scale were better able to survive $0.756 \mathrm{mg} H \mathrm{HCN}$ per liter than the nonresistant strain could survive $0.204 \mathrm{mg} \mathrm{HCN}$ per liter. These data indicate that both the resistant and the nonresistant scales become progressively more difficult to kill the older they become, up through the early second molt with the resistant strain and to the early gray adult with the nonresistant strain. After the early gray stage, there is a sudden drop in resistance in both strains. No attempt will be made to explain in this paper why those insects in the second molt of the resistant strain are the most resistant, while in the nonresistant strain those in the earlygray-adult stage are the most resistant.

\section{SUMMARY}

A high-peak type of HCN concentration, such as is obtained in field practice, offers a slight advantage over the low, uniform type of concentration in the range of dosages tried. Even though the differences are not great, the trend is toward more efficient control with the highpeak type of concentration.

High mortality of the nonresistant red scale was obtained with low dosages and short exposures. Very little difference in kill of the nonresistant red scale existed between the exposures of 15, 30, and $45 \mathrm{~min}$ utes. Unsatisfactory results were obtained with low dosages of $\mathrm{HCN}$ and short exposures on the resistant strain of red scale.

In nine out of eleven cases the 45-minute exposure gave slightly higher 
percentages of kill than the 30-minute exposure, on both the nonresistant and the resistant red scale, though the differences were not statistically significant.

When preconditioned at $50^{\circ} \mathrm{F}$ for 3 to 4 hours before fumigation, both the resistant and the nonresistant red scale showed a higher percentage of kill by fumigation than when preconditioned at $75^{\circ}$ or at $90^{\circ} \mathrm{F}$.

Under laboratory conditions, resistant red scales prefumigated with a sublethal dose of $\mathrm{HCN}$ just before fumigation gave a lower percentage of kill by fumigation than those that received no prefumigation treatment.

Nonresistant red scales prefumigated with a sublethal dose of HCN 1 hour before the regular fumigation gave a lower percentage of kill by fumigation than those that received no prefumigation treatment.

Resistant red scales that had been preconditioned at $50^{\circ} \mathrm{F}$ for 3 to 4 hours and then prefumigated with a low dosage of $\mathrm{HCN}$ before the regular fumigation, were more easily killed by $\mathrm{HCN}$ than those that were only prefumigated before the regular fumigation, but more insects survived than of those preconditioned at $50^{\circ}$ but not prefumigated. This indicates that preconditioning at $50^{\circ}$ does not overcome the effects of protective stupefaction.

Preconditioning the nonresistant red scale at $50^{\circ} \mathrm{F}$ overcame the effects of the prefumigation charge of $\mathrm{HCN}$, for the data indicate that no protective stupefaction occurred.

Of the stages of the nonresistant red scale tested, the motile young are the least resistant to $\mathrm{HCN}$, while the early gray adults are the most resistant.

Of the stages of resistant red scale treated, the motile young are also the least resistant to $\mathrm{HCN}$, but the scales in the second molt are the most resistant.

In both the nonresistant and the resistant strains of red scale, as the insects pass from the early gray adult to the late gray adult, they become more susceptible to $\mathrm{HCN}$ fumigation.

\section{ACKNOWLEDGMENTS}

The author wishes to express his appreciation to Professor H. J. Quayle for his helpful suggestions and criticisms, and to Mr. R. C. Dickson for assistance in counting scale. 


\section{LITERATURE CITED}

BLISs, C. I.

1935. The calculation of the dosage-mortality curve. Ann. Appl. Biol. 22:134-67.

Cupples, H. L.

1933. A consideration of "interval shooting" as practiced in eitrus fumigation. Jour. Econ. Ent. $26: 262-69$.

Dickson, R. C.

1941. Inheritance of resistance to hydrocyanic acid fumigation in the California red scale. Hilgardia 13(9):513-22.

GraY, G. P., and A. F. KirkPATRICK.

1929. The protective stupefaction of certain scale insects by hydrocyanic acid vapor. Jour. Econ. Ent. 22:878-92.

KIRKPATRICK, A. F.

1939. Summer scale control in coastal citrus areas. California Citrog. 24:359, 376.

LINDGREN, D. L.

1938. The stupefaction of red scale, Aonidiella aurantii, by hydrocyanic acid. Hilgardia 11(5):213-25.

MOORE, WILLIAM.

1933. Studies of the "resistant" California red scale Aonidiella aurantii Mask. in California. Jour. Econ. Ent. 26:1140-61.

1934. Fumigation experiments with California red scale under orchard conditions. Jour. Econ. Ent. 27:1042-55.

Peters, Gerhard.

1936. Chemie und Toxikologie der Schädlingsbekämpfung. 120 p. Ferdinand Enke, Stuttgart, Germany.

PratT, F. S., A. F. Swain, and D. N. EldRED.

1931. A study of fumigation problems: "Protective stupefaction," its application and limitations. Jour. Econ. Ent. 24:1041-63.

QUAXLE, H. J.

1920. Recent fumigation developments. California Citrog. $5(6): 188,189,193$.

1938. The development of resistance to hydrocyanic acid in certain scale insects. Hilgardia 11 (5) :183-210.

QUaYle, H. J., and P. W. Rohrbaugh.

1934. Temperature and humidity in relation to HCN fumigation for the red scale. Jour. Econ. Ent. 27:1083-95.

SNEDECor, George W.

1937. Statistical methods. 341 p. Collegiate Press, Inc., Ames, Iowa.

SwaIN, A. F.

1918. Fumigation experiments: the time factor. Jour. Econ. Ent. 11:320-24.

TORRE-BUENo, J. R. DE LA.

1937. A glossary of entomology. 336 p. The Science Press Printing Company, Lancaster, $\mathrm{Pa}$. 